\title{
The forgotten confounding variable of the very-low-caloric intervention in the ketogenic diet
}

\author{
Mohammed Abrahim (1) ${ }^{1}$
}

Received: 24 October 2020 / Accepted: 18 January 2021 / Published online: 9 February 2021

(c) The Author(s), under exclusive licence to Springer Science+Business Media, LLC part of Springer Nature 2021

\section{To the Editor:}

After reading the paper entitled "The ketogenic diet corrects metabolic hypogonadism and preserves pancreatic B-cell function in overweight/obese men: a single-arm uncontrolled study" published in Endocrine [1], I would like to make a contribution to the ongoing discussion of the dietary interventions in the management of obesity and its related metabolic disorders.

The hallmark of the ketogenic intervention is carbohydrate intake restriction of $<20-50 \mathrm{~g} / \mathrm{d}$ [2]. The caloric content of the ketogenic diet varies widely and, for that reason, it is crucial to consistently disclose the caloric content of the ketogenic diet under investigation. The intervention used in the aforementioned study was a very-low-calorie ketogenic diet (VLCKD). The degree of caloric restriction was severe, especially in the first phase, with a daily intake of only 600-800 Kcal. Despite this, the title neglected to mention the marked caloric deficit of the studied intervention.

A very-low-calorie diet (VLCD), without being ketogenic in nature, has been shown to normalize B-cell function and reverse type- 2 diabetes mellitus [3]. Furthermore, due to lack of control group and randomization, the results of the above study could well be solely attributed to the metabolic benefits of weight loss secondary to the caloric deficit rather than ketosis or the carbohydrate restrictive nature of the ketogenic diet.

To conclude, due to the significant metabolic impact of very-low-caloric restriction, the authors of the current paper propose to avoid using the term "ketogenic diet" without referencing its caloric value. The rationale behind this is that, when the studied dietary intervention is VLCKD, the resultant metabolic benefits could well be attributed solely or primarily to the VLCD rather than the ketogenic state.

\section{Compliance with ethical standards}

Conflict of interest The author declares no competing interests.

Publisher's note Springer Nature remains neutral with regard to jurisdictional claims in published maps and institutional affiliations.

\section{References}

1. S. La Vignera, R. Cannarella, F. Galvano, A. Grillo, A. Aversa, L. Cimino, C. M. Magagnini, L. M. Mongiò̀, R. A. Condorelli, A. E. Calogero, The ketogenic diet corrects metabolic hypogonadism and preserves pancreatic $ß$-cell function in overweight/obese men: a single-arm uncontrolled study. Endocrine (2020). https://doi.org/ 10.1007/s12020-020-02518-8

2. P. Trimboli, M. Castellana, D. Bellido, F.F. Casanueva, Confusion in the nomenclature of ketogenic diets blurs evidence. Rev. Endocr. Metab. Disord. 21, 1 (2020). https://doi.org/10.1007/s11154-02009546-9

3. M.E. Lean, W.S. Leslie, A.C. Barnes, N. Brosnahan, G. Thom, L. McCombie, C. Peters, S. Zhyzhneuskaya, A. Al-Mrabeh, K.G. Hollingsworth, A.M. Rodrigues, L. Rehackova, A.J. Adamson, F.F. Sniehotta, J.C. Mathers, H.M. Ross, Y. Mcllvenna, R. Stefanetti, M. Trenell, P. Welsh, S. Kean, I. Ford, A. McConnachie, N. Sattar, R. Taylor, Lancet 391, 541 (2018). https://doi.org/10.1016/S01406736(17)33102-1
Mohammed Abrahim

abrahimm@mcmaster.ca

1 McMaster University, Hamilton, ON, Canada 